\title{
PENGARUH TOTAL PENDAPATAN DAERAH DAN PAJAK DAERAH TERHADAP LAJU PERTUMBUHAN EKONOMI PROVINSI LAMPUNG
}

\author{
Defia Riski Anggarini ${ }^{1)}$ \\ email: defiaranggarini@gmail.com \\ 1) Manajemen, Universitas Teknokrat Indonesia \\ Jl. H.ZA Pagaralam, No 9-11, Labuhanratu,Bandarlampung \\ Email : pertama@gmail.com ${ }^{1)}$,kedua@ymail.com ${ }^{2)}$,ketiga@teknokrat.ac.id ${ }^{3)}$
}

\begin{abstract}
Abstrak
Penelitian ini bertujuan untuk mengetahui pengaruh total pendapatan daerah dan pajak daerah terhadap laju pertumbuhan ekonomi Provinsi Lampung. Penelitian ini menggunakan data sekunder dari BPS dan Kementrian Keuangan. Penelitian ini menggunakan analisis regresi linier ECM (error correction model). Hasil penelitian ini adalah total pendapatan daerah berpengaruh negatif terhadap pertumbuhan ekonomi dan panaj daerah berpengaruh positif terhadap pertumbuhan ekonomi.
\end{abstract}

Kata kunci: Total Pendapatan Daerah, Pajak Daerah dan Pertumbuhan Ekonomi.

\section{Pendahuluan}

\subsection{Latar Belakang}

UU Perimbangan Keuangan Pusat-Daerah (UU-PKPD) merupakan UU yang mengatur perimbangan keuangan atau desentralisasi fiskal antara Pemerintah PusatDaerah berdasarkan pembagian fungsi dan wewenang penyelenggaraan pemerintahan di antara pemerintah Pusat, Propinsi dan Kabupaten/Kota dalam UU tentang Pemerintahan Daerah.

Kebijakan otonomi daerah yang berkaitan dengan tiga asas desentralisasi, dekonsentralisasi, dan tugas pembantuan yang merupakan tiga landasan pokok dalam peyelenggaraan pemerintah didaerah.

Dalam rangka pelaksanaan otonomi daerah, maka daerah dituntut untuk semakin meningkatkan kemandirian keuangan daerahnya agar dapat melaksanakan dan membiayai urusan rumah tangga daerahnya. Untuk itu daerah perlu menggali sumber-sumber pajak dan retribusi yang cukup dalam melaksanakan urusan pemerintahan dan pembangunan. Hal ini sejalan dengan peraturan pemerintah RI nomor.38 tahun 2007 tentang pembagian urusan pemerintahan antara Pemerintah, Pemerintah Provinsi dan Pemerintah kabupaten/kota, yang menyatakan bahwa, "Otonomi daerah adalah hak dan wewenang daerah otonom untuk mengatur dan mengurus sendiri urusan pemerintahan dan kepentingan masyarakat setempat sesuai dengan peraturan perundang-undangan".

\subsection{Masalah}

Berdasarkan uraian mengenai latar belakang, maka permasalahan penelitian ini adalah
1. Apakah Total Pendapatan Daerah (TPD) berpengaruh terhadap pertumbuhan ekonomi Provinsi Lampung Tahun 2000-2013.

2. Apakah Pajak Daerah berpengaruh terhadap pertumbuhan ekonomi Provinsi Lampung Tahun 2000-2013.

\subsection{Tujuan}

Berdasarkan uraian mengenai permasalahan, maka tujuan dari penelitian ini adalah:

1. Untuk menganalisis pengaruh Total Pendapatan Daerah (TPD) terhadap pertumbuhan ekonomi Provinsi Lampung Tahun 2000-2013.

2. Untuk menganalisis pengaruh Pajak Daerah terhadap pertumbuhan ekonomi Provinsi Lampung Tahun 2000-2013.

\section{Pembahasan}

Penelitian ini menggunakan data sekunder yang bersumber dari BPS (Badan Pusat Statistik), Bank Indonesia, DPJK dan Dispenda Provinsi Lampung. Penelitian ini menggunakan model ECM (Error Corection Model) dan pengujian asumsi klasik serta analisis data menggunakan program Eviews 6.1.

Untuk mengetahui pengaruh variabel total pendapatan daerah (LnTPD), Pajak Daerah (LnTax) terhadap pertumbuhan ekonomi (PDRB) digunakan persamaan regresi linier berganda (Gujarati, 2004).

Dengan regresi dasarnya sebagai berikut:

$Y=\beta_{0}+\beta_{1} X_{1}+\beta_{2} X_{2}+\varepsilon$

Dan diaplikasi terhadap variabel:

$D(P D R B)=\beta_{0}+D(\beta 1 \operatorname{LnTPD})+D(\beta 2 \operatorname{LnTax})+\beta 3$

\section{Keterangan:}

$\mathrm{D}(\mathrm{PDRB})$

:Penyesuaian Logaritma Natural dari

Pertumbuhan Ekonomi Propinsi

Lampung dari Tahun 2000-2013.

D(LNTPD) : :Penyesuaian Logaritma Natural dari

Total Pendapatan Daerah Propinsi

Lampung dari Tahun 2000-2013.

D(LNTax) : :Penyesuaian Logaritma Natural dari

Pajak Daerah Propinsi Lampung dari

Tahun 2000-2013.

ECT(-1) :Hasil nilai residu dari persamaan

Sebelumnya. 
$\begin{array}{lll}\varepsilon & : & \text { Standar Error. } \\ \beta_{0} \ldots \beta_{3} & : & \text { Koefisien yang diestimasi. }\end{array}$

\subsection{Hasil Uji Stasioneritas}

Data yang digunakan dalam penelitian ini merupakan data time series. Aturan dasar dalam penggunaan data time series adalah harus dilakukannya uji stasioneritas, agar tidak terjadi regresi lancung sehingga data time series tersebut dapat digunakan kapan saja dan dalam kondisi apapun. Dibawah ini merupakan hasil uji stasioneritas pada ordo level $\mathrm{I}(0)$.

Tabel 1. Hasil Uji Stasioneritas Pada Orde Level 1(0) Jumlah observasi $=13$

\begin{tabular}{ccclc}
\hline Variabel & Intersep & $\begin{array}{l}\text { Intersep } \\
\text { dan } \\
\text { Trend }\end{array}$ & $\begin{array}{l}\text { Tanpa } \\
\text { Intersep } \\
\text { dan } \\
\text { Trend }\end{array}$ & Orde \\
\hline PDRB & - & - & 1.861737 & $\mathrm{I}(0)$ \\
& 1.447818 & 2.162901 & & \\
LnTPD & - & - & 2.543137 & $\mathrm{I}(0)$ \\
& 2.166496 & 4.130211 & & \\
LnTax & - & - & 2.776548 & $\mathrm{I}(0)$ \\
& 5.209319 & 29.94295 & &
\end{tabular}

Sumber : Hasil uji Unit root pada ordo level

Ket: $* * \quad$ : Berdasarkan tingkat kepercayaan $95 \%$

Hasil pengujian menunjukkan bahwa terdapat nilai statistik dari Phillips-Perron yang lebih besar dan lebih kecil dari nilai kritis MacKinnon; yang menunjukkan tidak semua variabel mengandung unit root atau dengan kata lain tidak semua data stationary pada orde level.

Karena hasil uji unit root dalam Tabel 2 menunjukkan menunjukkan tidak semua data/variabel mengandung unit root atau stationary pada orde level. Artinya apabila data semacam ini dipakai untuk mengestimasi persamaan, maka akan terjadi regresi lancung. Untuk mengatasi hal itu, maka langkah selanjutnya adalah melakukan uji stationeritas data pada First-Difference. Dibawah ini merupakan hasil uji stasioneritas pada orde First-Difference I(1)

Tabel 2. Hasil Uji Stasineritas Paa Orde FirstDifference I(1)

Jumlah observasi $=13$

\begin{tabular}{ccccc}
\hline Variabel & Intersep & $\begin{array}{l}\text { Intersep } \\
\text { dan } \\
\text { Trend }\end{array}$ & $\begin{array}{l}\text { Tanpa } \\
\text { Intersep } \\
\text { dan } \\
\text { Trend }\end{array}$ & Orde \\
\hline PDRB & - & - & - & $\mathrm{I}(1)$ \\
LnTPD & 4.641695 & 8.318147 & 4.332415 & \\
& - & - & - & $\mathrm{I}(1)$ \\
LnTax & 8.556051 & 7.897314 & 4.487969 & \\
& - & - & - & $\mathrm{I}(1)$
\end{tabular}

Sumber : Data Diolah, Eviews 6.1

Hasil uji unit root pada ordo First-Difference atas data yang dipakai dan disajikan pada Tabel 3 menunjukkan bahwa data dari seluruh variabel telah stasionary dan terintegrasi pada ordo yang sama, yaitu pada first difference $\mathrm{I}(1)$ dengan tingkat kepercayaan 95 persen.

\subsection{Uji Kointegrasi}

Uji kointegrasi yang dilakukan adalah dengan mengunakan metode yang dikembangkan oleh EngleGranger (EG). Berdasarkan uji kointegrasi yang dilakukan menggunakan metode yang dikembangkan oleh Engle-granger (EG) ini dengan melihat residual setiap estimasi. Dibawah ini merupakan table hasil uji kointegrasi.

Tabel 3. Hasil Uji Kointegrasi

Jumlah observasi $=13$

\begin{tabular}{llllc}
\hline Variabel & Intersep & $\begin{array}{c}\text { Intersep } \\
\text { dan } \\
\text { Trend }\end{array}$ & $\begin{array}{c}\text { Tanpa } \\
\text { Intersep } \\
\text { dan } \\
\text { Trend }\end{array}$ & $\begin{array}{c}\text { Ord } \\
\mathbf{e}\end{array}$ \\
\hline $\operatorname{RESID}(0$ & - & - & - & $1(0)$ \\
$1)$ & 1.900967 & 1.628806 & 2.045925 & \\
& $* *$ & $* *$ & $* *$ & \\
\hline
\end{tabular}

Sumber : Data Diolah, Eviews 6.1

Dari residual estimasi persamaan bahwa data stasionary pada ordo level atau I(0) maka menunjukkan bahwa variabel-variabel terkointegrasi yang berarti bahwa setiap variabel bebas mempunyai hubungan jangka panjang terhadap belanja modal. Setelah diketahui bahwa data terkointegrasi maka estimasi dapat dilakukan dengan menggunakan error correction model (ECM).

\subsection{Hasil Uji ECM}

Setelah dilakukan pengujian kointegrasi dengan menggunakan metode Engle-Granger (EG) pada persamaan kemudian dilakukan estimasi ECM dengan memberikan hasil seperti persamaan 4.3 di bawah ini.

$$
\begin{aligned}
\mathrm{D}(\mathrm{PDRB})= & -0.036389-0.612422 \mathrm{D}(\mathrm{LnTPD})+ \\
& {[-0.079016] \quad[-0.978311] } \\
& 1.581837 \mathrm{D}(\text { LnTax })-0.036389 \mathrm{D}(\mathrm{ECT}) \\
& {[1.472042] }
\end{aligned}
$$

$\begin{array}{ll}\text { Keterangan } & : \\ {[]} & : \text { t-statistik } \\ \mathrm{R}^{2} & : 0.36564 \\ \text { F-stat } & : 1.729243\end{array}$

D(PDRB) :Penyesuaian Pertumbuhan Ekonomi D(LnTPD) :Penyesuaian Logaritma Natural Total Pendapatan Daerah

D(Tax) :Penyesuaian Logaritma Natural Pajak

Daerah

ECT

:Merupakan nilai hasil yang di estimasi dari residual persamaan sebelumnya. 


\begin{tabular}{|c|c|c|c|c|}
\hline & $\begin{array}{c}\text { (LNTPD } \\
\text { ) } \\
\end{array}$ & $\begin{array}{c}\text { D(LNTA } \\
\mathrm{X}) \\
\end{array}$ & $\begin{array}{c}\text { RESID01( } \\
-1) \\
\end{array}$ & C \\
\hline I & 391875 & -0.137102 & -0.099185 & \\
\hline $\begin{array}{c}\text { D(LNTA } \\
\text { X) }\end{array}$ & -0 & 1 & -0.0 & -0323086 \\
\hline $\begin{array}{c}\text { RESID01 } \\
(-1)\end{array}$ & -0 & 66 & 0. & 61 \\
\hline C & -0.0 & -0.323086 & 0.068961 & 0.212089 \\
\hline
\end{tabular}

Dari hasil estimasi diketahui bahwa koefisien kesalahan ketidakseimbangan ECT secara statistik signifikan, berarti model spesifikasi ECM yang digunakan dalam penelitian ini adalah valid. Artinya model spesifikasi ECM dalam persamaan ini sukses. Nilai koefisien yang menunjukkan angka $|-0,55|$ yang berarti proporsi fungsi penyaluran dana pihak ketiga terhadap jumlah penyaluran dana pihak ketiga pada bank umum di Indonesia sebelumnya disesuaikan pada periode sekarang adalah $55.38 \%$ dan signifikan. Besarnya koefisien ECT juga menunjukkan bahwa variabel bebas memiliki penyesuaian yang cepat untuk kembali ke keseimbangan jangka panjang.

\subsection{Hasil Uji Asumsi Klasik}

\subsubsection{Uji Normalitas}

Uji ini digunakan untuk mengetahui apakah residual terdistribusi normal atau tidak. Gambar 2 dibawah ini adalah hasil uji normalitas.

\section{Gambar 1. Hasil Uji Normalitas}

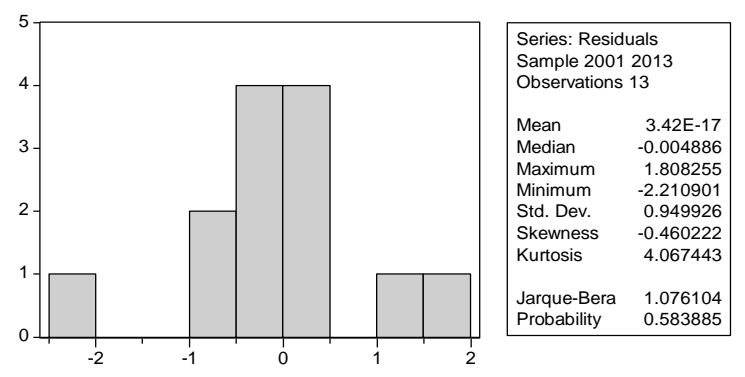

Sumber : Data Diolah, Eviews 6.1

Berdasarkan Gambar 1. Dapat dilihat bahwa asumsi normalitas telah terpenuhi, yaitu nilai probability atau tingkat signifikansi dari Uji Jarque Bera bernilai 0,831270 lebih besar dari taraf nyata (alpha) 0,05 atau tidak signifikan. Ini berarti bahwa residual menyebar secara normal.

\subsubsection{Uji Multikolinearitas}

Uji multikolinieritas bertujuan untuk menguji apakah pada model regresi ditemukan korelasi antar variabelvariabel bebas. Untuk mendeteksi ada tidaknya korelasi antar sesama variabel bebas, dapat dihitung dengan menggunakan metode covariance matrix. Dan selanjutnya dilihat nilai probabilitas dari uji covariance matrix sebagai berikut:
Tabel 4. Hasil Uji Multikolinearitas

Sumber: Data Diolah, Eviews 6.1

Dengan melihat hasil uji multikolinieritas menggunakan metode covariance matrix, diketahui bahwa perhitungan nilai korelasi seluruh variabel berada dibawah tingkat kepercayaan 0,05 atau lebih dari 0,05. Sehingga dapat disimpulkan bahwa tidak ada gejala multikolinieritas dalam model.

\subsubsection{Uji Heteroskedatisitas}

Heteroskedatisitas adalah keadaan dimana faktor gangguan tidak memiliki varian yang sama. Cara yang digunakan untuk mendeteksi ada tidaknya heteroskedastisitas adalah dengan uji White Heteroskedasticity. Dibawah ini adalah hasil Uji Heteroskedatisitas.

\section{Tabel 5. Hasil Uji Heteroskedatisitas}

White Heteroskedasticity Test:

\begin{tabular}{lcrc}
\hline \hline F-statistic & 0.372583 & Probability & 0.890322 \\
Obs*R- & 6.861404 & Probability & 0.651547 \\
squared & & & \\
Sumber: Data & Diolah, Eviews & 6.1
\end{tabular}

Tabel 5 di atas menunjukan bahwa nilai Probability Obs*R-Square adalah 6.861404 lebih besar dari taraf nyata (alpha) 5\%. Berarti dalam model penelitian ini terbebas dari gejala heteroskedastisitas.

\subsubsection{Uji Autokorelasi}

Autokorelasi adalah adanya korelasi antara anggota observasi satu dengan observasi lain yang berlainan waktu. Uji autokorelasi yang digunakan dalam penelitian ini adalah dengan menggunakan Breusch-Godfrey Serial Correlation LM Test. Dibawah ini adalah hasil Uji Autokorelasi

Tabel 6. Hasil Uji Autokorelasi

Breusch-Godfrey Serial Correlation LM Test:

\begin{tabular}{lll}
\hline \hline F-statistic & 1.039477 & Probability \\
Obs*R-squared & 2.976818 & Probability \\
\hline \hline
\end{tabular}

Sumber: Data Diolah, Eviews 6.1

Berdasarkan hasil uji autokorelasi pada Tabel 6 di atas, probabilitas yaitu sebesar 0.225732 lebih besar dari alpha 5\%. Maka dapat disimpulkan tidak terdapat masalah autokorelasi dalam penelitian ini.

\section{Kesimpulan}

Berdasarkan hasil penelitian, didapatkan bahwa:

1. Total Pendapatan Daerah (TPD) berpengaruh negatif terhadap Pertumbuhan Ekonomi Provinsi Lampung.

2. Pajak Daerah berpengaruh positif terhadap Pertumbuhan Ekonomi Provinsi Lampung. 


\section{Daftar Pustaka}

[1] Bank Indonesia. 2013. Kajian Ekonomi Regional. Jakarta

[2] Dinas Pendapatan Provinsi Lampung. 2013. Laporan Tahunan Penerimaan Daerah. Lampung

[3] Gujarati, N Damodar. 2004. Basic Econometrics, Fourth Edition. The McGraw-Hill Companies.

[4] Republik Indonesia. Undang-undang nomor 32 tahun 2004 tentang Pemerintah Daerah.

[5] Republik Indonesia. Undang-undang nomor 33 tahun 2004 tentang Perimbangan Keuangan Antara Pemerintah Pusat dan Pemerintah Daerah.

[6]Widarjono, Agus. 2005. Ekonometrika Pengantar dan Aplikasinya.Ekonisa.Jakarta. 